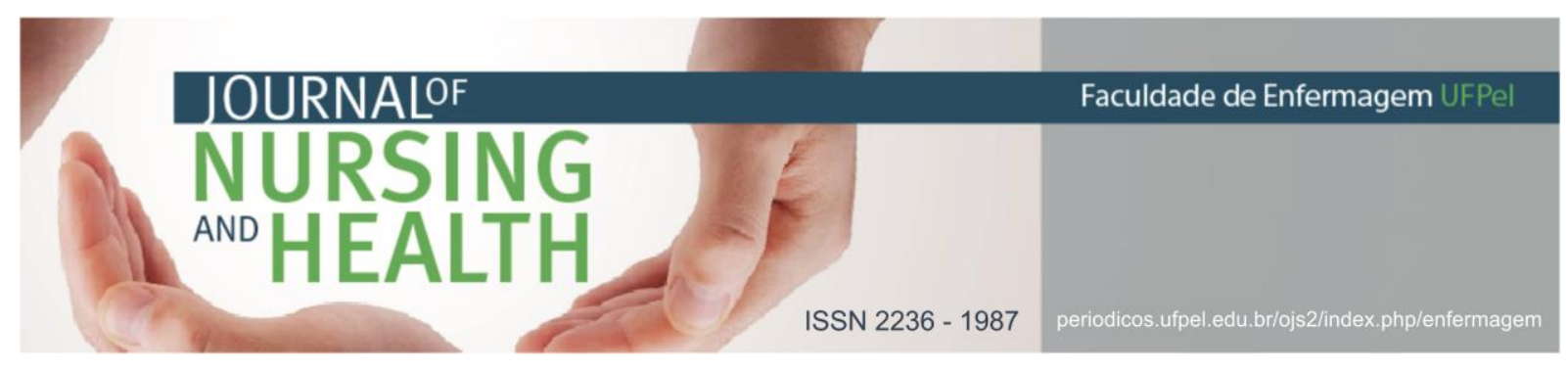

ARTIGO ORIGINAL

\title{
Sentimentos despertados nas mulheres frente ao diagnóstico de câncer de mama
}

\author{
Feelings awakened in women against the diagnosis of breast cancer
}

\section{Sentimientos despertados en las mujeres frente al diagnóstico de cáncer de mama}

Alvares, Rafaella Bortolassi ${ }^{1}$; Santos, Izabel Dayana de Lemos²; Lima, Nara de Morais ${ }^{3}$; Mattias, Silvia Regina ${ }^{4}$; Cestari, Maria Elisa Wotzasek ${ }^{5}$; Gomes, Natália Carolina Rodrigues Colombo ${ }^{6}$; Pinto, Keli Regiane Tomeleri da Fonseca ${ }^{7}$

\begin{abstract}
RESUMO
Objetivo: identificar os sentimentos despertados nas mulheres frente ao diagnóstico de câncer de mama. Método: trata-se de um estudo qualitativo, realizado no ambulatório de oncologia de um hospital universitário, com 11 mulheres diagnosticadas com câncer de mama e idade entre 43 e 58 anos. A coleta de dados foi realizada por meio de entrevista semiestruturada, de maio a julho de 2015. Os dados foram analisados e interpretados conforme a análise de conteúdo. Resultados: após a análise emergiram três categorias: o impacto do diagnóstico; a vivência prévia da doença, o autoconhecimento e sua aceitação; esperança embasada na fé em Deus. Considerações Finais: a maioria das mulheres demonstraram-se extremamente sensibilizadas com o diagnóstico de câncer de mama e aflitas diante da incerteza da morte; outras, por já terem vivenciado a doença em um ente próximo, sentiram-se mais fortes e reagiram melhor ao diagnóstico.
\end{abstract}

Descritores: Saúde da mulher; Neoplasias da mama; Diagnóstico.

\section{ABSTRACT}

Objective: to identify the feelings aroused by women in the diagnosis of breast cancer. Method: this is a qualitative study, performed at the oncology outpatient clinic of a university hospital, with 11 women diagnosed with breast cancer and aged between 43 and 58 years. Data collection was performed through a semi-structured interview, from May to July 2015. Data were analyzed and interpreted according to content analysis. Results: three categories emerged after the analysis: the impact of the diagnosis; the previous experience of the disease, self-knowledge and its acceptance;

\footnotetext{
${ }^{1}$ Enfermeira. Especialista em Saúde da Mulher pela Universidade Estadual de Londrina/UEL. Londrina (PR). Brasil. E mail: rafabortolassi@hotmail.com http://orcid.org/0000-0002-5785-8628

Enfermeira. Mestranda do Programa de Pós-graduação em Enfermagem, Universidade Estadual de Londrina/UEL. Londrina (PR). Brasil. Email: izabellemos87@hotmail.com http://orcid.org/0000-0003-3559-5350

${ }^{3}$ Enfermeira Obstétrica. Universidade Estadual de Londrina/UEL. Londrina (PR). Brasil. Email: nara_lima_@hotmail.com http://orcid.org/0000-0003-2904-7606

${ }^{4}$ Enfermeira. Especialista em Saúde da Mulher pela Universidade Estadual de Londrina/UEL. Londrina (PR). Brasil. Email: silmattias@yahoo.com.br http://orcid.org/0000-0003-2749-3960

${ }^{5}$ Enfermeira. Doutora em Ciências. Docente do Departamento de Enfermagem da Universidade Estadual de Londrina/UEL. Londrina (PR). Brasil. Email: elisaluiz@uol.com.br http://orcid.org/0000-0001-9485-6878

${ }^{6}$ Enfermeira. Doutoranda em Enfermagem. Docente do Departamento de Enfermagem da Universidade Estadual de Londrina/UEL. Londrina (PR). Brasil. Email: nataliacolombogomes@hotmail.com http://orcid.org/0000-0003$3770-8558$

${ }^{7}$ Enfermeira Obstétrica. Doutoranda em Saúde Coletiva. Docente do Departamento de Enfermagem da Universidade Estadual de Londrina/UEL. Londrina (PR). Brasil. Email: tomeleri@yahoo.com.br http://orcid.org/0000-0003-1280-8421
} 


\section{JOURNALOF

hope grounded in faith. Final Considerations: most women were extremely sensitive to the diagnosis of breast cancer and afflicted by the uncertainty of death, others because they had experienced the disease in a nearby entity felt stronger and reacted better to the diagnosis.

Descriptors: Women's health; Breast neoplasms; Diagnosis.

\section{RESUMEN}

Objetivo: identificar los sentimientos despertados por las mujeres frente al diagnóstico de cáncer de mama. Método: se trata de un estudio cualitativo, realizado en el ambulatorio de oncología de un hospital universitario, con 11 mujeres diagnosticadas con cáncer de mama y edad entre 43 y 58 años. La recolección de datos fue realizada por medio de entrevista semiestructurada, en los meses de mayo a julio de 2015. Los datos fueron analizados e interpretados según el análisis de contenido. Resultados: después del análisis surgieron tres categorías: el impacto del diagnóstico; la vivencia previa de la enfermedad, el autoconocimiento y su aceptación; esperanza basada en la fe. Consideraciones finales: la mayoría de las mujeres se mostraron extremadamente sensibilizadas con el diagnóstico de cáncer de mama y aflicciones ante la incertidumbre de la muerte, otras por haber vivido la enfermedad en un ente cercano se sintieron más fuertes y reaccionaron mejor al diagnóstico.

Descriptores: Salud de la mujer; Neoplasias de mama; Diagnóstico.

\section{INTRODUÇÃO}

De acordo com o Instituto Nacional de Câncer (INCA), o impacto do câncer na população corresponda a $80 \%$ dos mais de 20 milhões de casos novos estimados para 2025, a estimativa para o Brasil, no biênio 2016-2017, indica cerca de 600 mil casos novos de câncer, correspondendo a 180 mil casos de câncer de pele não melanoma, 61 mil cânceres de próstata e 58 mil casos de câncer de mama em mulheres. ${ }^{1}$ Assim, o câncer de mama é um dos mais frequentes no Brasil, sendo o tipo de câncer que mais acomete as mulheres após o câncer de pele ${ }^{2}$, e a maior causa de morte por câncer entre as mulheres. ${ }^{3}$

Sabe-se que a detecção precoce do nódulo mamário ainda é o mais preconizado, sendo de fundamental importância para a redução das taxas de morbidade e mortalidade dessa neoplasia. ${ }^{4}$ Um estudo evidencia que quanto mais cedo a doença é descoberta, maiores são as chances de cura. ${ }^{5}$

Contudo, a notícia do diagnóstico de uma doença como o câncer, que ainda popularmente é associado ao sofrimento e a morte, causa enorme impacto na mulher e em sua família. ${ }^{6}$ Assim, a notícia do câncer de mama é recebida pelas mulheres com muito sofrimento, sentindo-se inseguras e angustiadas com a evolução da doença e do tratamento. ${ }^{7}$

Considerando a relevância do tema, associado a alta incidência e ao fato das mulheres e suas famílias terem suas vidas modificadas pela doença, foi formulada a seguinte questão de pesquisa: o que as mulheres sentem ao receberem o diagnóstico de câncer de mama? Buscando ampliar os conhecimentos, este estudo tem por objetivo identificar os sentimentos despertados nas mulheres frente ao diagnóstico de câncer de mama. 


\section{NURSING \\ aNO HEALTH \\ ISSN 2236 - 1987}

\section{MÉTODO}

Este estudo descritivo, com abordagem qualitativa, foi desenvolvido no Ambulatório de Oncologia do Hospital Universitário Norte do Paraná (HUNPR), em Londrina-PR. Inicialmente foi realizada a busca dos prontuários das mulheres atendidas no Ambulatório e diagnosticadas com câncer de mama, entre o período de janeiro de 2013 a dezembro de 2014 e que estavam em tratamento da doença. Depois da identificação das mulheres, foi realizado contato telefônico para informar sobre a pesquisa e convidá-las para participar da mesma. Nos casos de aceitação, foram agendadas visitas domiciliares para a coleta dos dados.

Foram elegíveis para a pesquisa 63 mulheres, das quais 11 participaram da pesquisa. Os critérios de inclusão foram: ter estado em tratamento no Ambulatório de Oncologia do HUNPR, residir na zona urbana do município e ter contato telefônico no prontuário. Foram excluídas do estudo mulheres que estavam com diagnóstico de câncer de mama em fase terminal (seis mulheres), moradoras da zona rural (quatro mulheres) ou de outro município (14 mulheres), não conseguido contato via telefone/telefone desatualizado para agendamento da entrevista (24 mulheres) e recusa (quatro mulheres).

A coleta de dados foi realizada no período de maio a julho de 2015 , sendo realizada uma entrevista com a seguinte questão norteadora: o que você sentiu quando recebeu 0 diagnóstico de câncer de mama doença? As entrevistas foram gravadas e transcritas na íntegra logo após sua realização, para que nenhum detalhe fosse excluído, procurando relembrar gestos, expressões, entonação de voz etc. Para manter o anonimato, as mulheres foram identificadas com a letra $M$ seguida do número correspondente à ordem da entrevista. A duração média do encontro da pesquisadora com as mulheres foi de 45 minutos, considerando a interação inicial e a entrevista propriamente dita.

Para a delimitação do número de participantes, utilizou-se o método saturação de dados, que ocorre quando se inicia a redundância das falas. Trata-se de uma ferramenta conceitual de que se faz muito uso em investigações qualitativas realizadas em vários campos da área da saúde. Esse critério indica o momento, em que as informações começam a ficar repetitivas e não surgem novos dados. ${ }^{8}$

As análises foram feitas através da análise de conteúdo ${ }^{9}$, que se divide em três fases: a pré-análise, a exploração do material, e o tratamento dos resultados: inferências e interpretação. A fase de pré-análise compreende a organização dos documentos, leitura flutuante, escolha dos relatos, formulação de hipóteses e elaboração de indicadores para fundamentar a interpretação. A fase de exploração do material consistiu em encontrar grupamentos e associações que respondem ao objetivo do estudo, surgindo assim, as categorias. Já a fase de tratamento dos resultados abrange o momento em que são feitas as inferências e a interpretação dos resultados encontrados. 


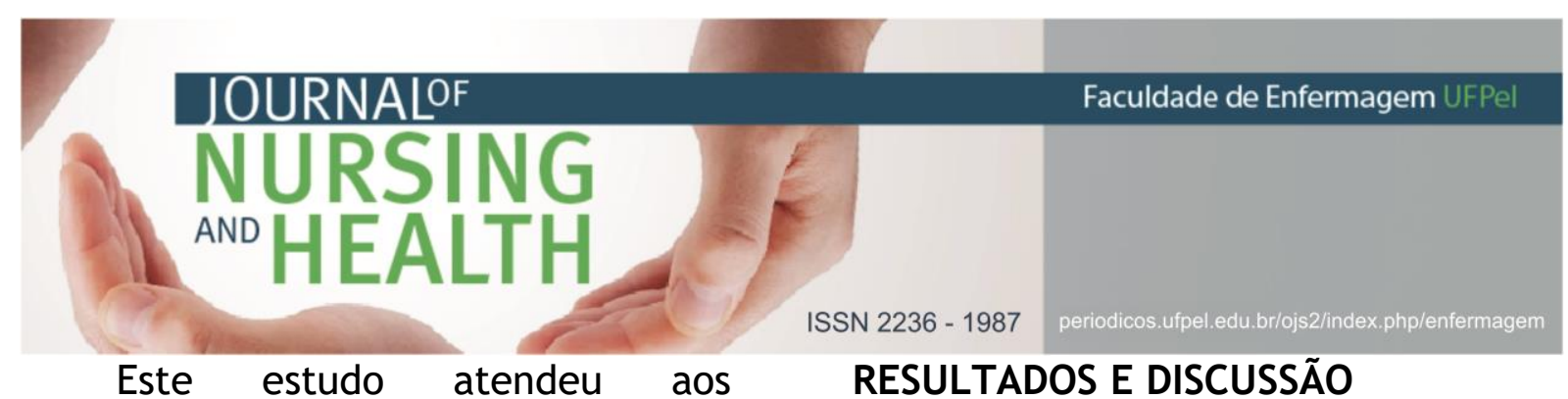
requisitos propostos pela Resolução $\mathrm{n}^{\circ}$. 466/2012 do Conselho Nacional de Saúde ${ }^{10}$, que dispõe sobre as normas e diretrizes regulamentadoras da pesquisa envolvendo seres humanos. Dessa forma, obteve-se de todas as mulheres o Termo de Consentimento Livre e Esclarecido. É um recorte da pesquisa intitulada "Câncer de mama: compreendendo a vivência da mulher e do companheiro", e foi aprovado pelo Comitê de Ética em Pesquisa da Universidade Estadual de Londrina, sob o Certificado de Apresentação para Apreciação Ética (CAAE) $\mathrm{n}^{\circ}$. 46547215.5.0000.5231.

\section{RESULTADOS E DISCUSSÃO}

Inicialmente foi traçado a caracterização sociodemográfica, obstétrica e ginecológica das mulheres com diagnóstico de câncer de mama. Após a análise dos relatos, foi possível identificar três categorias: "O impacto do diagnóstico", "A vivência prévia da doença, o autoconhecimento e sua aceitação", e "Esperança embasada na fé em Deus".

Na Tabela 1 estão demonstradas as características sociodemográficas das mulheres com diagnóstico de câncer de mama. A Tabela 2 apresenta as informações referentes às características obstétricas e ginecológicas das mulheres com diagnósticos de câncer de mama.

Tabela 1. Características sociodemográficas das mulheres com diagnóstico de Câncer de mama. Londrina, 2015

\begin{tabular}{ll}
\hline Características sociodemográficas & $\mathbf{n}$ \\
\hline Idade & \\
49 anos ou menos & 8 \\
50 anos ou mais & 3 \\
Escolaridade & \\
$\quad$ Fundamental completo & 4 \\
$\quad$ Médio completo & 3 \\
$\quad$ Superior Completo & 4 \\
Estado Civil & \\
$\quad$ Casada & 6 \\
Viúva & 3 \\
Separada & 2 \\
RaçalCor da mãe & \\
Branca & 7 \\
Preta & \\
Renda Familiar & \\
$\quad$ Até um salário mínimo & \\
Entre $1-4$ salários mínimos & 1 \\
Mais de 4 salários mínimos & 9 \\
\hline
\end{tabular}


Tabela 2. Características obstétricas e ginecológicas das mulheres com diagnóstico de Câncer de mama. Londrina, 2015

\begin{tabular}{lc}
\hline Características obstétricas e ginecológicas & $\mathbf{n}$ \\
\hline Menarca & 2 \\
Antes dos 10 anos & 9 \\
10-15 anos & \\
Sexarca & 10 \\
15-20 anos & 1 \\
Após os 20 anos & \\
Uso de contraceptivo & 3 \\
Nunca usou & 6 \\
Usou por até 5 anos & 2 \\
Usou por mais de 10 anos & \\
Número de gestações & 6 \\
1-3 gestações & 4 \\
4 gestações ou mais & 1 \\
Nã̃o teve gestação & \\
História de amamentação & 9 \\
Sim & 1 \\
Não & \\
História familiar de câncer de mama (mãe ou irmã) & 7 \\
Sim & 4 \\
Não & \\
\hline
\end{tabular}

\section{Impacto do diagnóstico}

Ao receberem o diagnóstico de câncer de mama, a maioria das mulheres referiu sentimentos como desespero, nervosismo, medo, descrença e não aceitação da doença. Conforme os relatos a seguir, as mulheres reviveram lembranças das experiências anteriores de outra pessoa que já havia tido a doença e seus sentimentos foram permeados pela morte, sofrimento, dor, perda da mama e do cabelo.

Ah eu fiquei desesperada [...] eu queria na hora que eu soube, eu queria que fosse de brincadeira aquilo, eu achava que era o fim para mim, eu comecei a ficar nervosa, a chorar [...] eu não aceitava a doença [...] não sabia por que tinha acontecido isso comigo, eu não aceitava. (M2)

Quando me deram o diagnóstico eu me assustei, a gente pensa só em morte, né? Quem morreu, quem sofreu, quem você viu passar dor, quem perdeu a mama, quem perder cabelo, e eu estava vendo a minha mãe naquele processo todo ali. (M8)

Apesar dos avanços científicos, o câncer de mama ainda é vinculado à dor e ao sofrimento, por causa dos tratamentos agressivos e mutiladores, somados às características da doença e elevada mortalidade. Por isso é fortemente associado a sentimentos negativos, pois acarreta grandes mudanças no dia a dia da mulher, causando várias alterações em sua vida, provocando mudanças na rotina 


\section{IOURNAIOF

doméstica, no âmbito profissional e nas relações afetivas. ${ }^{7}$

Foi quando ele me falou, daí eu fiquei desesperada [...] fiquei nervosa naquela hora ali eu nem queria voltar para minha casa [...]. (M10)

Você tem a raiva, você não gosta, mas tipo podia não estar aqui hoje. (M4)

0 câncer faz com que sentimentos de desespero, nervosismo, medo, descrença, não aceitação da doença sejam despertados diante da dor e do sofrimento da mulher ${ }^{11}$, sentimentos considerados normais, pois estão associados ao medo do desconhecido, já que muitas mulheres nunca vivenciaram momentos semelhantes $^{12}$, considerando 0 pior momento de sua vida. ${ }^{13}$

Por se tratar de uma doença estigmatizante, o câncer causa à mulher grande abalo psicossocial, e ainda está muito associado ao mau prognóstico, ao sofrimento, à incurabilidade, à dependência de outras pessoas e ao tratamento agressivo. ${ }^{14}$

A vivência prévia da doença, o autoconhecimento e aceitação

Algumas mulheres relataram que já sentiam que o diagnóstico de câncer de mama seria positivo, por já terem vivenciado esse câncer na família.

Eu sabia que ia dar positivo né [...] aí eu olhei para o meu pai e falei: "Papai e agora? A gente está passando isso com a mamãe, e agora?" (M1)
Como eu já tinha passado "isso" com a minha mãe [...] eu acho que meio que eu já tinha vivenciado isso, então acho que ficou mais fácil para mim. (M5)

A história familiar é um importante fator de risco para o desenvolvimento de câncer de mama. Estudo indica que o risco aumenta duas vezes, se parentes de primeiro grau (mulheres) tiveram câncer de mama, de quatro a seis vezes, se o câncer de mama ocorreu em dois familiares de primeiro grau e também aumenta, se a mãe foi afetada por câncer de mama antes dos 60 anos. ${ }^{15}$

Outras mulheres já esperavam o diagnóstico pela percepção do nódulo no seio, demonstrando autoconhecimento do corpo e autocuidado.

Como eu me senti? Ah, normal [...] você fala assim do choque, se eu fiquei chocada? Não, eu não fiquei, recebi como se fosse uma notícia normal [...] eu mesma recebi a notícia, mas não me choquei não, eu já esperava, então, quando recebi, eu já esperava [...] pelo tamanho, quando eu passei a mão e que eu já calculava o que seria [...] então, não me abalou no meu psicológico, não. (M3)

Cabe salientar que a história de câncer na família faz com que a mulher tenha um autoconhecimento mais eficiente e também passe a desenvolver o autocuidado, que inclui o autoexame das mamas como uma estratégia para o reconhecimento de alterações em sua mama. 


\section{JOURNAIOF

Por estarem mais preparadas, seja por já terem vivenciado situação parecida, seja por terem identificado o nódulo na mama, essas mulheres demonstraram uma melhor aceitação da doença, tendo reações mais tranquilas e amenas frente ao diagnóstico.

Tranquila, eu fiquei tranquila, não me desesperei [...] fui tranquila, muito tranquila [...], até as pessoas que viram minha reação, né? Admirou de ver minha tranquilidade, minha calma, passar por isso eu passei, graças a Deus, hoje estou aqui para testemunhar. (M9)

A aceitação da doença pode ser expressa de várias maneiras, podendo ser caracterizada pelo desejo de que o tratamento se inicie e que tudo ocorra o mais rápido possível, com isso buscando a cura, ou pela mudança no significado do câncer, enfrentando-o sem medo, ou ainda, sendo a aceitação a única opção que resta à mulher. ${ }^{16}$

\section{Esperança embasada na fé em Deus}

A fé em Deus foi um sentimento despertado pelas mulheres como a principal aliada e geradora de esperança e força tanto no momento do diagnóstico, quanto no enfrentamento da doença e no tratamento.

Ihhh! Não foi fácil [...] mas eu sempre estive assim, eu sempre, eu sou evangélica, né? Sempre tive Deus no meu coração e fé, sempre acreditando que Deus tem um propósito para tudo. (M1)
Fui pedindo a Deus e vi que aquilo que eu tinha não era assim [...] ter que abandonar tudo [...] e foi onde começou a minha vida no acompanhamento no HC. (M2)

Tenho muita fé em Deus. Foi como se uma voz me dissesse: "fica firme que você não está sozinha" (M4).

[...] quando saí do laboratório, com o resultado [...] "se for câncer mesmo tudo vai dar certo, tenho muita fé em Deus" [...] me preparei, minha fé, aquilo que acredito - e não acreditei que iria sofrer [...] sempre acreditei que o que aparece na vida da gente temos que encarar. (M8)

Assim, a fé incondicional e a confiança em Deus aparecem como os principais aliados dessas mulheres em todo o processo da doença. A fé religiosa promove esperança, equilíbrio e fortalecimento, favorecendo a luta pela vida e a serenidade para aceitar a doença. A fé ajuda essas mulheres a recomeçar suas vidas e a compreender essa nova fase que vivenciam.

Com a esperança depositada em Deus, elas passam a ver esse momento de forma positiva. Por isso, é de grande importância que se compreenda o significado da religião para essas mulheres durante 0 processo de adoecimento, pois assim é possível criar estratégias de promoção à saúde que visem diminuir os sofrimentos por ele gerados. ${ }^{7}$

A fé é caracterizada como uma das redes de apoio social e percebe-se que, para as participantes, atuou como 


\section{JOURNALOF \\ NURSING \\ AND HEALTH}

ISSN 2236 - 1987

doença, sentiram-se mais fortalecidas para sua aceitação e enfrentamento.

0 sentimento de fé em Deus, embasada em crenças e na espiritualidade, foram relatadas em grande parte das entrevistas, demonstrando ser um suporte favorável, um alento para sanar medos e angústias, e fonte de força para que as participantes da pesquisa pudessem encarar o diagnóstico, tratamento e todas as mudanças geradas pela doença.

Enquanto limitações do estudo, ressalta-se que os resultados apresentados constituem somente os sentimentos despertados no momento do diagnóstico da doença, não sendo capaz de retratar os sentimentos das mulheres durante a vivência do tratamento do câncer. Outra limitação foi a ausência ou desatualização do número de telefone no prontuário, impossibilitando a captação de um número maior de mulheres.

Com este estudo, foi possível conhecer os sentimentos despertados pelas mulheres diante do diagnóstico de câncer de mama e a importância de identifica-los para promover um cuidado e uma assistência integral, contudo, novos estudos devem ser realizados buscando descrever a vivência dessa mulher, após o diagnóstico.

\section{REFERÊNCIAS}

1. Ministério da Saúde (BR). Instituto Nacional de Câncer José Alencar Gomes da Silva (INCA). Coordenação de Prevenção e Vigilância. Estimativa 2016: Incidência de câncer no Brasil [Internet]. Rio de Janeiro: INCA; 2015 
[acesso em 2015 jul 29]. Disponível em: http://www.inca.gov.br/wcm/dncc/2 015/por-incidencia.asp

2. Sousa CNS, Santiago CMC, Pereira WO, Morais FRR. Perfil epidemiológico do câncer: estudo em um hospital de oncologia e hematologia. J nurs UFPE on line [Internet]. 2012 may [acesso em 2018 fev 10]; 6(5):968-76. Disponível em:

https://periodicos.ufpe.br/revistas/r evistaenfermagem/article/view/7159 127582

3. Silva RCF, Hortale VA. Rastreamento do Câncer de Mama no Brasil: Quem, Como e Por quê? Rev bras cancer [Internet]. 2012 [acesso em $2018 \mathrm{fev}$ 18];58(1):67-71. Disponível em: http://www.inca.gov.br/Rbc/n_58/v0 1/pdf/10b_artigo_opiniao_rastreamen to_cancer_mama_brasil_quem_como_ por_que.pdf

4. Martins CA, Guimarães RM, Silva RLPD, Ferreira APS, Gomes FL, Sampaio JRC, et al. Evolução da Mortalidade por Câncer de Mama em Mulheres Jovens: Desafios para uma Política de Atenção Oncológica. Rev bras cancer [Internet]. 2013 [acesso em 2018 fev 18];59(3):341-9. Disponível em: http://www1.inca.gov.br/rbc/n_59/v 03/pdf/04-artigo-evolucao-

mortalidade-cancer-mama-mulheresjovens-desafios-politica-atencaooncologica.pdf

5. Azim HA, Michiels S, Bedard PL, Singhal SK, Criscitiello $C$, Ignatiadis $M$, et al. Elucidating prognosis and biology of breast cancer arising in young women using gene expression profiling. Clin cancer res [Internet]. 2012 Jun [cited 2018 fev 18];18(5):1341-51.
Available from: http://www.ncbi.nlm.nih.gov/pubme d/22261811

6. Neris RR, Anjos ACY. Experiência dos cônjuges de mulheres com câncer de mama: uma revisão integrativa da literatura. Rev esc enferm USP [Internet]. 2014 [acesso em 2017 jun 03];48(5):922-31. Disponível em: http://www.scielo.br/pdf/reeusp/v48 n5/pt_0080-6234-reeusp-48-05922.pdf

7. Carvalho CMS, Amorim FCM, Silva RTS, Alves VF, Oliveira ADS, Monte NS. Feelings of women diagnosed with breast cancer. Rev enferm UFPE online [Internet]. 2016 [acesso em 2017 mai 22];10(11):3942-50. Disponível em: https://periodicos.ufpe.br/revistas/r evistaenfermagem/article/view/1147 6/13323

8. Fontanella BJB, Luchesi BM, Saidel MGB, Ricas J, Turato ER, Melo DG. Amostragem em pesquisas qualitativas: proposta de procedimentos para constatar saturação teórica. Cad saude publica [Internet]. 2011 [acesso em 2015 jul 29]; 27(2):389-94. Disponível em: http://www.scielo.br/pdf/csp/v27n2 /20.pdf

9. Bardin L. Análise de Conteúdo. $4^{\mathrm{a}}$ ed. Lisboa: Edições 70 Lda; 2011.

10. Ministério da Saúde (BR). Conselho Nacional de Saúde. Resolução 466, de 12 de dezembro de 2012: diretrizes e normas regulamentadoras de pesquisa envolvendo seres humanos [Internet]. [acesso em 2016 nov 01]. Disponível em:

http://bvsms.saude.gov.br/bvs/saude legis/cns/2013/res0466_12_12_2012.h tml 


\section{ISSN $2236-1987$}

11. Ribeiro AL, Almeida CSL, Reticena KO, Maia MRG, Sales CA. A enfermagem no cuidado paliativo domiciliar: o olhar do familiar do doente com câncer. Rev RENE [Internet]. 2014 [acesso em 2016 nov 21];15(3):499-507. Disponível em: http://www.revistarene.ufc.br/revist a/index.php/revista/article/viewFile/ $1668 / \mathrm{pdf}$

12. Frohlich M, Benetti ERR, Stumm EMF. Experiences of women with breast cancer and actions to reduce stress. Rev enferm UFPE on line [Internet]. 2014 [acesso em 2016 jan 13]; 8(3):537-44. Disponível em: https://periodicos.ufpe.br/revistas/r evistaenfermagem/article/view/9708 19780

13. Almeida TG, Comassetto I, Alves KMC, Santos AAP, Silva JMO, Trezza MCSF. Vivência da mulher jovem com câncer de mama e mastectomizada. Esc Anna Nery [Internet]. 2015 [acesso em 2016 mar 06];19(3):432-8. Disponível em: http: / / www.scielo.br/pdf/ean/v19n3 /1414-8145-ean-19-03-0432.pdf

14. Tarricone V Jr, Tarricone SP, Duarte NB, Luft NM, Ambar RF. Comunicação do diagnóstico de câncer de mama. Rev bras mastologia [Internet]. 2015 [acesso em 2017 fev 15]; 20(1):27-32. Disponível em: http://www.rbmastologia.com.br/wp

content/uploads/2015/06/Masv20n1_ web1.pdf

15. Ministério da Saúde (BR). Instituto Nacional de Câncer José Alencar Gomes da Silva (INCA). Diretrizes para a detecção precoce do câncer de mama no Brasil. [Internet] Rio de Janeiro: INCA; 2015. [acesso em 2015 jul 29]. Disponível em: http://www1.inca.gov.br/inca/Arquiv os/livro_deteccao_precoce_final.pdf

16. Otani MAP, Barros NF, Marin MJS. A experiência do câncer de mama: percepções e sentimentos de mulheres. Rev baiana enferm [Internet]. 2015 [acesso em 2017 jul 03];29(3):229-39. Disponível em: https://portalseer.ufba.br/index.php /enfermagem/article/view/12701

17. Arrieira ICO, Thofehrn MB, Milbrath VM, Schwonke CRGB, Cardoso DH, Fripp JC. O sentido da espiritualidade na transitoriedade da vida. Esc Anna Nery [Internet]. 2017. [acesso em 2018 abr 22];21(1):e20170012. Disponível em:

http://www.scielo.br/pdf/ean/v21n1 /1414-8145-ean-21-01-e20170012.pdf

18. Canieles IM, Muniz RM, Corrêa ACL, Meincke SMK, Soares LC. Rede de apoio a mulher mastectomizada. Rev enferm UFSM [Internet]. 2014 [acesso em 2017 mai 10]; 4(2):450-8. Disponível em: https: //periodicos.ufsm.br/reufsm/ar ticle/view/10790

19. Koenig HG. Espiritualidade no cuidado com o paciente. $2^{a}$ ed. São Paulo: Jornalística; 2012.

Data de submissão: 29/09/2017

Data de aceite: 20/01/2018

Data de publicação: 04/05/2018 